\title{
А.Г. Костерев
}

\section{ФЕНОМЕН СОВЕТСКОГО ТЕХНОКРАТИЗМА: К ПОСТАНОВКЕ ПРОБЛЕМЫ (ПОЛИТИКО-ИДЕОЛОГИЧЕСКОЕ И СОЦИАЛЬНО-КУЛЬТУРНОЕ ИЗМЕРЕНИЯ)}

\begin{abstract}
С новых позиций актуализируется проблема советского технократизма. Рассматривается вопрос применимости понятия технократизма к советской системе управления. Анализируются культурно-исторические истоки и особенности советского способа управления социально-экономическим и научно-техническим развитием. Очерчиваются социальные границы и рамки действия советской техноструктуры. Историческая судьба отечественной технократии иллюстрируется рядом биографических примеров. Формулируются перспективные проблемы исследований механизмов взаимосвязей власти, науки и техники в советском государстве.

Ключевые слова: советское государство; технократия; социальная история науки и техники; советская наука.
\end{abstract}

Последние десятилетия российское общественнополитическое пространство демонстрирует нам целый ряд сколь симптоматичных, столь и закономерных тенденций, тесным образом связанных между собою. Во-первых, очевиден перманентный кризис управления, в состоянии которого отечественная государственность пребывает вот уже треть века. Во-вторых, на фоне этого кризиса в современном политическом дискурсе и медийном пространстве муссируется тема неких «технократов» как части представителей управленческой элиты, что позволяет предположить актуализацию самого понятия технократизма в сфере властных отношений и государственного управления. Отчасти подтверждением этому могут служить периодически встречающиеся в блогосфере упоминания так называемых методологов («игротехников») - занимающих ключевые посты и должности последователей философско-управленческого учения, разработанного в середине ХХ в. А.А. Зиновьевым, Э.В. Ильенковым, Г.П. Щедровицким и М.К. Мамардашвили. Наконец, сам объект управления - современное российское общество (причем сегодня становится все более понятным, что именование его «постсоветским» указывает не на хронологические, а на ценностно-смысловые координаты) - продолжает переживать окончание советской эпохи, что, с одной стороны, в известном смысле блокирует механизмы социальной рефлексии и адаптации к изменившимся реалиям, с другой же порождает в его сознании соответствующие мифологемы, становящиеся факторами текущих социальноэкономических и политических процессов и используемые властью в рамках социального управления. Диалектический же характер взаимодействия субъекта и объекта управления неизбежно приводит к тому, что советское прошлое, все еще являясь фактом общественного сознания, не теряет своей актуальности и для современных государственных управленцев, оборотной стороной чего становится мифологизация советского опыта в коллективном сознании правящих кругов, в частности - советского управленческого опыта.

В свете всего этого видится целесообразным вновь обратиться к проблеме советского технократизма как исходной аксиологической позиции государства и стилевой черте его управленческих практик. В перспективе это позволит перевести вопрос в практическую плоскость относительно того, насколько применим советский опыт социального управления в современных условиях.

При множественности толкований самого термина «технократизм», а также контекстов его употребления, в качестве отправной точки для анализа советского его варианта остановимся на представлении о технократизме как элементе механизма взаимосвязи политики, науки и техники в условиях техногенной цивилизации. Данный подход был в общих чертах заявлен С.А. Зубковым [1] и, несмотря на неоднозначность сделанных в итоге выводов, представляется достаточно продуктивным, прежде всего применительно к развитым индустриальным обществам, к числу которых относилось и советское.

Следует добавить, что в данном контексте своеобразным «приводным ремнем» указанного механизма являлся, пожалуй, главный кадровый ресурс советской технологической модернизации - слой инженернотехнических работников (шире - научно-техническая интеллигенция). Именно эту социальную группу в контексте ее взаимоотношений с советской партгосноменклатурой и вовлеченности в процессы социального управления и предполагается расположить в фокусе исследования, призванного в конечном счете выявить социально-политическую сущность и степень технократизма советской управленческой системы.

Принято считать, что в обществоведческий оборот термин «технократия» был введен американским инженером У.Г. Смитом в 1919 г. Особую же роль научнотехнических специалистов в индустриальном обществе, потенциально претендующих на управление не только технологическими, но и социально-экономическими и даже политическими процессами, впервые отметил американский футуролог Т.Б. Веблен в 1921 г. [2].

В нашем случае важно не путать технократию с экспертократией (современной тенденцией к засилью в различных сферах разного рода экспертов) и пресловутым «технологическим императивом» (вырастающей из евро-американских футуристических утопий ориентацией на практическое воплощение всего тех- 
нически возможного). Первая в советских реалиях как таковая практически отсутствовала, второй имел достаточно серьезные организационные и технологические ограничения. Иными словами, говоря о советском технократизме, мы будем иметь в виду не только и не столько форму власти, сколько характеристику ментальных и социокультурных процессов (если угодно некий агрегированный показатель уровня рефлексии при принятии управленческих решений). В этом ракурсе предстоит разделить и сфокусироваться на двух вещах: мировоззрении и самоощущении (целях) советской технократической прослойки, с одной стороны, и содержании и механизмах реальных процессов принятия решений с той или иной долей ее участия (средствах) - с другой.

Также следует различать условных советских «технократов» (часть научного и инженерного сообществ, интегрированную во власть) и «технобюрократов» (профессиональных чиновников среднего уровня, имевших то или иное отношение к социально значимым технологиям). Социально-функциональная роль технократизма в отечественном хронотопе заключается в том, что его социальная база - слой научно-технических кадров, возникший в результате модернизационных попыток XIX-XX вв., - использовался высшей политической властью для формирования технобюрократии, деятельность которой контролировалась и направлялась этой властью. С другой стороны, технократизм как «идеология» соответствующих социальных групп объективно отражал их притязания на доступ к политической власти.

Кроме того, отдельной строкой следует упомянуть и такую категорию, как региональные технократы, являвшуюся частью региональной элиты. В контексте властной стратификации советской системы региональную элиту можно определить как слой управленческих кадров, занимавший промежуточное положение между партийно-государственной элитой и массами. В первом приближении региональную технократическую элиту можно считать частью правящей элиты, являвшуюся при этом самостоятельной социальной группой, главной особенностью которой было наличие относительно четко структурированных представлений о своей роли (миссии) в обществе и соответствующих определенным образом выраженных корпоративных интересов. Что их объединяло и отличало от других групп советского социума? Высшее техническое или естественное образование и занятие управленческой деятельностью в самом широком понимании (иногда занятие государственных или партийных должностей). Необходимо иметь в виду, что значительная часть советских региональных технократов занималась изучением, освоением и управлением местными производительными силами (в первую очередь это касается Сибири). При этом эффективное управление ресурсами ахиллесова пята отечественной государственности. Можно предположить, что в том числе и здесь кроются корни позднесоветского внутриэлитного противостояния ведомственной и местной бюрократии (этот разлом не мог не затронуть и инкорпорированную в нее прослойку технократов).
Задаваясь вопросом о том, насколько применимы категории «технократия» и «технократизм» для описания советской системы принятия управленческих решений, нужно принимать во внимание весь разброс мнений относительно этой проблемы, вызванный во многом тем, что каждый из высказывающихся понимает данные дефиниции по-своему. Наиболее распространенные трактовки сводятся к уже упоминавшимся выше двум позициям: «чистый» технократизм как возможность / необходимость доступа к принятию экономических и политических решений ученых и инженеров и технократизм в более широком смысле, подразумевающий под технократией власть технобюрократии («хозяйственников», «красных директоров»). Подобного рода политологические и социологические подходы практически не проливают свет на логику действий самого советского руководства, обладая малым объяснительным потенциалом. Гораздо предпочтительнее здесь выглядит социально-исторический подход, с помощью которого, возможно, получится приблизиться к пониманию того, как носившиеся в интеллектуальной атмосфере первой половины - середины XX столетия технократические конструкты взаимодействовали со складывавшейся и уже сложившейся в СССР системой управления (критически важны здесь научно-техническая политика и управление социальной прослойкой самих носителей идейного заряда технократизма), меняли ли они ее либо же сами менялись под ее воздействием.

При этом следует помнить, что в самом советском дискурсе технократизм третировался как одно из направлений «буржуазной философии». Причины этого можно усмотреть и в опасениях правящей партии за свою монополию на политическую власть, и в противопоставлении официальной идеологией гуманистической составляющей социализма неизбывно свойственному западному капитализму отчуждению, и, наконец, во вполне отчетливо осознаваемом собственном технологическом отставании от глобального идеологического же конкурента (ведь одним из критериев идейного превосходства как раз и было технологическое первенство).

В перестройку по понятным причинам был сформулирован тезис: «Псевдо-технократизм советского общества - это идеологическое прикрытие для административно-командной системы» [3. С. 52]. О самих же потенциальных технократах тот же исследователь говорит: «Что касается инженерно-технического персонала, ученых, других работников умственного труда, то административно-командная система намеренно препятствовала их полноценному социальному развитию, не желая, чтобы эта “технократическая элита" заняла подобающее ее знаниям, профессиональной компетенции место в системе социального управления» [Там же. С. 53]. Отсюда делается вывод о том, что ложная технократизация советского общества в 1950-1970-е гг., проходившая за счет расширения сети политехнических вузов и НИИ, а следовательно, и численного роста ИТР, «превратила управленческие кадры в полупрофессионалов-полубюрократов, не умеющих по-деловому руководить и не знающих экономики» [3. С. 53], что, в свою очередь, и обусло- 
вило крах всей советской управленческой системы. Здесь возникает вполне закономерный вопрос: была ли способна псевдотехнократическая система сформировать потенциально опасный для нее слой пускай даже столь же потенциальной технократической контрэлиты?

Современные исследования технократизма при всем своем многообразии в целом не отрицают наличия в недрах советского социума и властных структур элементов технократии. Тем не менее наиболее конструктивные из них опять-таки склонны привязывать их к конкретным (и, что самое главное, разным) социальным стратам: инженерно-технической интеллигенции (советским «белым воротничкам») [4] и все тем же технобюрократам-хозяйственникам [5]. Это ни в коей мере не умаляет вклада их авторов в воссоздание социально-психологического и социально-исторического портретов советской технократии соответственно, но не дает общей ее картины.

В конечном итоге, исходя из разницы означенных двух посылов, специалисты в массе своей склонны приходить к двум полярным, по сути, выводам: либо советская система последовательно давила ростки технократизма, облекаясь при этом в ложные его формы, либо же наоборот - сама постепенно пропитывалась им, что впоследствии во многом способствовало ее перестроечному демонтажу. Последний вариант наиболее емко выражен в очерке А.Н. Николаева [Там же]. Интуиция (не столько, впрочем, научная, сколько обыденная) подсказывает, что истина расположена где-то посередине. В любом случае это предстоит выяснить в ходе дальнейших изысканий.

Приступая к поиску и выявлению сущности отечественной технократии, для начала стоит задаться вопросом о потенциальных истоках ее генезиса. Во-первых, это, конечно же, условный «технократизм» большевиков-революционеров, вооруженных марксистским учением, экономико-технологический детерминизм которого явно перекликался с базовыми основаниями технократических идей. Во-вторых, сюда же следует отнести имманентный технократизм советских ученыхадминистраторов, участвовавших в создании советской «большой науки» в период 1930-1950-х гг. и в ходе этого процесса объективно становившихся частью советской элиты [6]. В-третьих, нельзя сбрасывать со счетов и определенный интуитивный технократизм советских управленцев среднего и нижнего звена (тех самых технобюрократов), формировавшийся у них в результате шедших параллельным курсом процессов технизации управления.

Если же посмотреть еще глубже, то можно заметить, что присущие технократическому видению мира идеи глобального проектирования (помимо идеологов большевизма) исповедовали К.Э. Циолковский и В.И. Вернадский, что в каком-то смысле позволяет считать русский космизм своего рода предтечей советского технократизма. Уже в 1920-е гг. к нему добавились крайне популярные в то время идеи социальной инженерии, пришедшие из Америки, бывшей, к слову сказать, для В.И. Ленина образцом прогресса (главным образом, технического и организационного).
Отсюда и будут видны примерные контуры социальной базы искомого советского технократизма, включавшей в себя одновременно (что критически важно) и часть верхушки партноменклатуры, и администраторов от науки, и «красных директоров». Всех вместе их можно рассматривать в качестве «техноструктуры» (по Дж. Гэлбрэйту) по отношению к советскому государству как условной корпорации.

Примерные рамки существования советской техноструктуры: середина 1930-х - середина 1980-х гг. Они обусловлены становлением и расцветом в СССР «большой науки», основанной на принципах централизованного планирования исследований, осуществлявшихся на базе сети специализированных институтов. Это, с одной стороны, формировало запрос на рост числа носителей высшего политехнического образования (ядра техноструктуры), с другой - стимулировало их выдвижение на руководящие должности, что и задавало необходимый минимум объективных условий для появления возможности складывания технократии как управленческого феномена. Тем самым неизбежно менялись ценностные ориентации правящего номенклатурного сословия в сторону постепенной его деидеологизации. В то же самое время инкорпорация ведущих научных кадров в советскую систему (прежде всего в систему руководства и управления наукой) делала их не только советскими учеными, но и в какой-то степени администраторами-чиновниками, расширяя круг возможностей и одновременно накладывая свой отпечаток на образ мышления и принятие управленческих решений [7]. Это, кстати, напрямую выводит на достаточно интересную и перспективную проблему социальной идентичности научноадминистративной элиты 1930-1950-х гг., ковавшей советскую «большую науку» и таким образом становившейся частью советской техноструктуры. Сохраняла ли она, будучи родом из Российской империи, старую интеллигентскую идентичность или же по ходу структурирования системы советского социума постепенно приобретала некую новую («технократическую»)?

Рождение советской системы управления - первая половина XX в. - время беспрецедентных экономических, социальных и политических катаклизмов. Нормативно-ценностные конструкты модерна сгорели в горниле двух мировых войн. Безоглядная вера в поступательный прогресс и будущее как последовательно улучшающееся настоящее уступала место фрустрации, обесценивавшей настоящее и обесцеливавшей будущее. Реакцией модерна на симптомы распада своей культурной матрицы стал ответ на футурофобию взрывом социального утопизма, носившего на этот раз героическо-мессианский характер (от ретрофутуристичных итальянского фашизма и Эрец Исраэль до экстремальных Земшарной советской республики и Третьего рейха) и ориентированного на радикальный прорыв в будущее. В наследство же от распадающегося модерна осталась сформировавшаяся еще на рубеже XIX-XX вв. установка на научное управление техническим и социальным прогрессом, неизбежно приводившая к самоценности управляемости социальной системы. Все это объективно давало исключительно благодатную почву 
для привития и укоренения технократических идей на ниве социального управления в большевистском государстве.

Советский проект как таковой был предельно футуристичен по содержанию и технократичен по форме. Являвшаяся его основным «средством доставки» плановая модель социально-экономического развития зона ответственности советских технократов - часто критиковалась и критикуется с позиций так называемого «калькуляционного аргумента» (невозможности рационального распределения ресурсов в плановой экономике). Но в данном случае следует иметь в виду, что он был прежде всего проектом глобальным, т.е. являлся некой новой универсальной культурной платформой, задающей поле возможностей для реализации проектов более низкого уровня, к которым уже применима критика с подобных позиций («Колумбова проблема») [8].

И, как ни странно, теоретически эта проблема могла быть решена в рамках идеи о создании системы автоматизированного управления экономикой, изначально предложенной пионером советской кибернетики А.И. Китовым (проект создания Единой государственной сети вычислительных центров) и продолженной академиком В.М. Глушковым в виде разработки проекта Общегосударственной автоматизированной системы учета и обработки информации (ОГАС). Во всяком случае научная технократия как минимум предложила это решение. Другое дело, что она последовательно проиграла в межведомственной схватке за него сначала руководству Минобороны, а затем своей «единокровной сестре» - технобюрократии из Центрального статистического управления [9]. Это, по всей вероятности, можно считать одной из причин того, что Советский Союз, худо-бедно вписавшийся в первую волну НТР, не вошел в крутой поворот второй ее волны.

Со схожей судьбой сюда же вплотную примыкала и разработанная под руководством академика Н.П. Федоренко коллективом Центрального экономико-математического института АН СССР Система оптимального функционирования экономики (СОФЭ), основанная на математическом моделировании и прогнозировании экономических процессов. Более того, сотрудник ЦЭМИ Б.Н. Михалевский разработал прогноз развития советской экономики на 1970-1980-е гг., предрекавший ей скорую стагнацию и кризис. Донести подготовленный доклад до председателя Госплана, зампреда Совмина СССР Н.К. Байбакова попытался Н.П. Федоренко, но потерпел неудачу и был вынужден уничтожить документ как противоречащий принятой программе партии, предусматривавшей построение коммунизма к 1980 г. [10].

Еще один пример - жизнь и судьба дважды репрессированного П.Г. Кузнецова. Идейный наследник русского космизма и сам «космический коммунист», занимавшийся социальной метафизикой советского строя, разрабатывал основы физической экономики [11]. Непосредственное практическое отражение его идеи научного прогнозирования и планирования нашли в работах хозрасчетного Сектора сетевого планирования и управления при Научно-исследовательском секторе
МГПИ (преобразованном позднее в Лабораторию систем управления разработками систем). В 1970 г. лаборатория была закрыта, а сам П.Г. Кузнецов репрессирован во второй раз (весьма характерно - помещен в психиатрический институт им. Сербского), что, в принципе, можно считать условным началом конца советского мегапроекта - точкой разрыва с футуристическим наследием русского космизма и раннесоветской эпохи, окончательного отрешения от поиска новых форм идейного содержания, самозамыкания в этих формах и, наконец, примата формы над содержанием. Это примерно совпало и с отказом от дальнейших попыток реформирования советской экономической системы. Знаковым в контексте личной и научной судьбы этого ярчайшего представителя советской техноструктуры было и само его имя - Побиск (Поколение Октября, Борцов И Строителей Коммунизма).

Из этого следует принципиально важный вывод о том, что ключевой особенностью советской технократии была ее вторичность - служебно-подчиненное положение по отношению к советскому мегапроекту (как минимум до исчерпания его футуристического заряда), попытка воплощения которого собственно и вызвала ее к жизни. Иными словами, не советские технократы определяли целевые и инструментальные параметры управления социально-экономической системой, но она сама посредством специфического идеологизированного дискурса формировала комплементарный ей тип технократии, качественные характеристики которого обусловливались соответствующими системными ограничениями. Отсюда подспудно и проистекала управляемость самой технократии по отношению к партийно-государственной системе (что, в частности, проявилось в феномене «управляемой науки»). Это определило следующие сущностные черты советской техноструктуры: этатизм, жесткую увязку социального прогресса с прогрессом научнотехнологическим, лояльность к идеям сверхцентрализации систем управления обществом и распределения ресурсов. Поэтому и неудивительно, что и третья попытка (две первые были адресованы Н.С. Хрущеву) А.И. Китова достучаться с идеей ОГАС до руководства страны, предпринятая уже в перестройку, не возымела должного действия [12].

В этом ключе весьма показательна участь одного из первых советских «технократов» (по духу), крупного организатора науки, инициатора создания и руководителя Научно-технического отдела ВСНХ академика Н.П. Горбунова, расстрелянного по «делу альпинистов» несмотря на всю свою предельную лояльность системе. По злой иронии судьбы с альпинизмом связана гибель и последнего крупнейшего организатора советской науки, «отца» нелинейной оптики - академика Р.В. Хохлова, которого не удалось спасти во многом из-за вмешательства в процесс его лечения Политбюро. Глубоко же символичным здесь представляется тот факт, что в обоих случаях фигурировала высочайшая вершина страны Советов - пик Коммунизма. Высота была открыта экспедицией под руководством Н.П. Горбунова, в дальнейшем неудачно участвовавшего в ее покорении; Р.В. Хохлов также 
пытался штурмовать ее, но, как и Н.П. Горбунов, не шел нескольких сот метров до вершины, и эта попытка стала для него роковой.

Со всем этим связан еще один момент - проблема социальной и политической ответственности советской технократии (при несомненном наличии примеров научного и гражданского мужества ее представителей) в самом широком смысле этого слова. Естественнонаучный материализм вкупе с марксистским диаматом порождал иррациональную по своей сути веру в некий «объективный» ход вещей, задававшую не активнодеятельностную, но пассивно-созерцательную позицию по отношению к социальной реальности и ограничивавшую общегражданскую ответственность отдельно взятого советского технократа рамками конкретного участка его работы. Там он мог вполне упорно и самоотверженно работать, но все, что выходило за пределы его прямой и непосредственной компетенции, его мало интересовало, а если и интересовало, то мотивация что-то всерьез менять была недостаточно высока для приложения сколько-нибудь серьезных усилий. Данный парадокс значительно снижал уровень технократизма управленческих кадров, обесценивая саму идею рационалистического подхода к управлению. Это во многом объясняет позднезастойную спячку советской технократии, очнувшейся только уже по ходу перестройки. Предположительно, истоки указанного явления кроются за пределами собственно сферы взаимоотношений советской власти и научно-технической сферы (памятуя русский космизм как идейную предпосылку зарождения советского технократизма), уходя в глубинные основания отечественной культуры, что, конечно же, требует отдельного исследования, общие контуры которого, впрочем, уже намечены [13].

Оборотной стороной данного свойства советской «технократической» культуры стал закономерный паттерн - подгонять объективную реальность под представления о ее должном состоянии. Вообще разрыв и конфликт между должным и сущим выражал собой главное конструкционное напряжение всей советской системы. Вероятно, это и стало важнейшей причиной краха самого проекта (как говорит культуролог В.В. Штепа, «если утопии не сбываются, то сбываются антиутопии»). Отсюда вытекает и то, что любая неудача в реализации мегапроекта воспринимается как ошибка проектировщиков, происки врагов, форсмажорные обстоятельства внешнего характера. Адекватность же самого мегапроекта под сомнение если и ставится, то в самую последнюю очередь. Ярким тому подтверждением может служить репрессивная практика советского государства по отношению к собственной технократии (особенно первого призыва - Шахтинское дело, дело Промпартии). Схема детально разобранной оппозитарной диалектики должного и сущего, апробированная на отечественном историкокультурном материале И.Г. Яковенко [14], может плодотворно применяться и для реконструкции истории советской техноструктуры.

Настоящий modus operandi и обусловил грани технологичности советской системы управления. Формировавшаяся ею социальная реальность - продукт соци- альных технологий, невиданных доселе как по масштабу, так и по своему качественному содержанию. Но очередной парадокс в том, что любая технология имплицитно подразумевает максимальную возможность контроля над процессами, протекающими в системе. Тем самым технократизм социальных управленцев бессознательно склонен к созданию ситуации искусственной стагнации социума. В особенной степени это проявилось в ходе попытки осуществления советского мегапроекта. Несмотря на то, что цель здесь зачастую оправдывала средства (технократизм, как правило, предусматривает принятие принципиально новой этики), сам набор этих средств и границы их применения всегда жестко определялись параметрами текущего идеологизированного политического дискурса. Поэтому все проблемы советской системы (даже сугубо технические) упирались в конце концов в идеологию, ограничения которой усугубляли обрисованные свойства советской технократии. Фактически отказывая себе в возможностях полного использования технократического ресурса, система вырисовывала порочный замкнутый круг проблем, не имевших приемлемого решения в ее масштабах, загоняя, таким образом, сам проект и его идеологическую составляющую в тупик (парадокс Лефора). Очевидным это стало именно в эпоху «развитого социализма», когда численность советской техноструктуры и доля ее присутствия в высших сферах управления достигли своего пика.

На фоне всего этого впервые об «инновациях» в Советском Союзе заговорили еще в начале 1980-х гг. в стенах Всесоюзного научно-исследовательского института системных исследований [15]. Характерно, что антиинновационность советской социально-экономической системы тесно соседствовала и неплохо уживалась с фетишизацией «научно-технического прогресса» и даже с верой в то, что им можно управлять (в 1972 г. была разработана первая Комплексная программа научно-технического прогресса и его социальноэкономических последствий). Иначе говоря, советские технократы, будучи по идейному складу своему поздними детьми XIX в., верили в некую «прогрессивность» XX столетия самого по себе (можно предположить, что косвенно это произрастало из марксистского тезиса о технологическом прогрессе как одном из факторов наступления коммунизма), в то время как по сути своей НТР - это и есть комплекс целенаправленных мер, в совокупности составляющий инновационную политику, одной из главных черт которой является отказ от жестких иерархических структур. При этом своеобразный псевдокульт «науки и техники» исповедовался при явном приоритете техники: сама по себе «чистая» наука не поощрялась - любые занятия научной деятельностью (показательно, что для этого был даже введен специальный термин - «научные работники») целью своей должны были иметь непосредственную техническую отдачу.

Одна из причин тому - все та же идеологическая (всепобеждающее учение Маркса-Ленина и вера в прямое управление всей социально-экономической системой), непосредственно выразившаяся в телеологическом подходе патриарха советского планирования 
С.Г. Струмилина. Отсюда и такое же «машинное», механистическое отношение к обществу, характерное для советских социальных инженеров. Хотя справедливости ради стоит признать, что советская система управления породила и программно-целевой метод, разработанный В.А. Базаровым-Рудневым. В этой связи примечательно, что планирование научной деятельности на заре советского государства стартовало одновременно с планированием социально-экономическим (помимо Особого временного комитета науки при СНК РСФСР этим вопросом занимался также и Госплан).

Другую причину можно обозначить как организационно-технологическую: количество в ущерб качеству (в надежде на то, что по законам диалектики первое рано или поздно перейдёт во второе). Бытийный смысл этой стратегии раскрывается крылатой фразой все того же С.Г. Струмилина: «Лучше стоять за высокие темпы, чем сидеть за низкие». Как результат - реализация коммунистического мегапроекта советской техноструктурой превратилась в попытки прорваться в постиндустриальное социально-экономическое пространство, измеряемое традиционными индустриальными категориями, что и было, в частности, отражено в принятой в 1961 г. на XXII съезде КПСС третьей программе партии. В принципе, это было обусловлено известным редукционизмом как одной из сущностных черт технократизма вообее: свести сложное к простому путем отделения главного от второстепенного, что выражалось в конечном итоге в том, что все многообразие социальной реальности сводилось к набору ограниченного числа контролируемых параметров (плановых показателей). На практике же это выливалось в то, что директивный план сам по себе становился самодовлеющим элементом социального управления: в случаях и научного планирования экономики, и планирования научной деятельности усилия по выполнению (и составлению отчетности) плана затмевали собой и подменяли реальный инновационный менеджмент.
Такого рода подмена цели средством не могла не привести к ситуации, в которой средство якобы демонстрировало свою эффективность (что автоматически нашло свое отражение в коллективном сознании и социальной памяти прежде всего правящего слоя и отчасти управляемых), но цель все-таки не была достигнута. В итоге же дискредитированным оказалось не средство, а цель.

Исходя из этого, можно сделать промежуточный вывод, заключающийся в том, что социальнополитическая система, сформировавшаяся в результате прежде всего индустриально-технологического рывка, безусловно, породила собственную техноструктуру, что было вполне закономерным явлением. Эта техноструктура, состоявшая из нескольких уровней, столь же объективно порождала, в свой черед, определенные элементы технократии как формы мировосприятия и установки социального управления. При этом сама советская техноструктура так и не стала самостоятельным политическим субъектом (или же, вероятно, не успела им стать), регулярно проигрывая номенклатуре в столкновениях по тем или иным проблемам управления. Это позволяет говорить о своего рода «гибридном» характере советской системы управления социально-экономическим и научно-техническим развитием: наличие общих черт планомерного научного подхода соседствовало с догматически-механистичным прочтением реальности, обращавшим технократию в прислугу идеократии, а технократические практики в ритуально-симулирующие компоненты карго-культа прогресса, науки и техники.

Определяя направления дальнейших исследований, стоит остановиться на двух, представляющихся наиболее перспективными: историко-культурные корни и основания данного феномена, а также характер и степень его влияния на постсоветскую систему социального управления.

\section{ЛИТЕРАТУРА}

1. Зубков С.А. Взаимосвязь политики, науки и техники в условиях техногенной цивилизации (социально-философские аспекты) : автореф. ... д-ра филос. наук. М., 2006.

2. Веблен Т.Б. Инженеры и ценовая система / пер. с англ. И. Кошкина; под науч. ред. А. Смирнова; Нац. исслед. ун-т «Высшая школа экономики». М. : Изд. дом Высш. шк. экономики, 2018. 112 с.

3. Титаренко Л.Г. Псевдотехнократизм в советском обществе: социально-философский анализ // Социс. 1991. № 7. С. $48-54$.

4. Абрамов Р.Н. Советские технократические мифологии как форма «теории упущенного шанса»: на примере истории кибернетики в СССР // Социология науки и технологий. 2017. № 2. С. 63-79.

5. Николаев А.Н. Становление и трансформация советской технократической элиты // Вестник ПНИПУ. Культура. История. Философия. Право. 2018. № 2. С. 83-95. DOI: 10.15593/perm.kipf/2018.2.07.

6. Костерев А.Г., Литвинов А.В. Профессорско-преподавательский корпус высшей школы в контексте советской модернизации // Вестник Томского государственного университета. 2016. № 403. C. 69-78. DOI: 10.17223/15617793/403/12.

7. Земцов Б.Н. Советский технократизм в 1917 - 1930-е годы ХХ века // Гуманитарный вестник (МГТУ им. Н.Э. Баумана) : электронный журнал. 2014. № 3 (17). URL: http://hmbul.ru/articles/187/187.pdf

8. Касавин И.Т. Мегапроекты и глобальные проекты: наука между утопизмом и технократизмом // Вопросы философии. 2015. № 9. С. 40-57.

9. Кутейников А.В. Академик В.М. Глушков и проект создания принципиально новой (автоматизированной) системы управления советской экономикой в 1963-1965 гг. // Экономическая история. Обозрение. М., 2011. Вып. 15. С. 139-156.

10. Петраков Н.Я. Размышления над новой книгой. Академик Федоренко о жизни и о себе // Вестник Российской академии наук. 1999. Т. 69, № 9. С. $840-842$.

11. Дёмин А.Н. Методологические и мировоззренческие уроки Побиска Георгиевича Кузнецова (к 85 -летию со дня рождения) // Человек. Сообщество. Управление. 2009. № 2. С. 32-41.

12. Кутейников А.В., Шилов В.В. Последняя попытка реанимировать проект общегосударственной автоматизированной системой управления советской экономикой (ОГАС). Письмо А.И. Китова М.С. Горбачёву, 1985 // Вопросы истории естествознания и техники. 2013. № 2. С. 100-109.

13. Музыкантский А.И., Яковенко И.Г. Манихейство и гностицизм: культурные коды русской цивилизации. М., 2011.320 с.

14. Яковенко И.Г. Должное и сущее как категории культурно-исторического процесса (на материале России) : автореф. ... канд. культурол. наук. М., 1999.

15. Структура инновационного процесса : труды конференции. М. : ВНИИСИ, 1981. 
Kosterev Anton G. Tomsk State University of Control Systems and Radioelectronics (Tomsk, Russia). E-mail: antonkosterev@rambler.ru THE PHENOMENON OF SOVIET TECHNOCRATISM: TO THE FORMULATION OF THE PROBLEM (POLITICALIDEOLOGICAL AND SOCIO-CULTURAL DIMENSIONS).

Keywords: Soviet state; technocracy; social history of science and technology; Soviet science.

In the article, the problem of Soviet technocracy is again actualized from a new perspective. The question of the applicability of the concept of technocracy to the Soviet system of governance is being considered. Summarizing a certain result of research in this area, there is a variety of existing research positions in relation to this phenomenon. The cultural-historical origins and features of the Soviet way of managing socio-economic and scientific-technical development are analyzed, which makes it possible to speak about it as part of an unrealized socio-utopian megaproject. On the basis of the socio-historical approach, the roots and prerequisites for the formation of elements of technocracy in the Soviet system are revealed. As part of this, it is proposed to consider the Soviet political and economic system as a corporation, and the layer of scientists-administrators and "red directors" integrated into power - as its technostructure. Outlines the social boundaries and scope of the Soviet technostructure, thereby removing the false opposition of the scientific-technical intelligentsia and techno-bureaucracy as its constituent parts. Special attention is paid to analyzing the problems of the practice of Soviet socio-economic planning and attempts to solve them by the Soviet technostructure. In this regard, the historical fate of the national technocracy is illustrated by the most striking examples of the personal and scientific destinies of its major representatives. This allowed us to conclude that the key feature of the Soviet technocracy was its secondary nature - its subordinate supercentralization of the systems of social management and resource allocation. Directly indicated features appeared in inherited from the XIX century objectivist attitudes regarding scientific and technological progress, which had a decisive influence on managerial decision-making in the fields of scientific planning and scientific planning. Based on the indicated range of questions, a theoretically significant conclusion is drawn about the hybrid nature of the Soviet system of governance, which contained certain elements of technocracy, the reconstruction of the social meanings of from this, the prospective problems of researching the mechanisms of interrelations of power, science and technology in the Soviet evolution and whose actions have a positive cognitive potential only in the deep historical context of the national culture. Proceeding state formulated position in relation to the Soviet megaproject. This also results in the main features of the Soviet technostructure: statism, a rigid linkage of social progress with scientific and technological progress, loyalty to the ideas of socialism.

\section{REFERENCES}

1. Zubkov, S.A. (2006) Vzaimosvyaz' politiki, nauki i tekhniki v usloviyakh tekhnogennoy tsivilizatsii (sotsial'no-filosofskie aspekty) [The relationship of politics, science and technology in terms of technological civilization (socio-philosophical aspects)]. Abstract of Philosophy Dr. Diss. Moscow.

2. Veblen, T.B. (2018) Inzhenery i tsenovaya sistema [The Engineers and the Price System]. Translated from English by I. Koshkin. Moscow: HSE.

3. Titarenko, L.G. (1991) Psevdotekhnokratizm v sovetskom obshchestve: sotsial'no-filosofskiy analiz [Pseudo-techcratism in Soviet society: a sociophilosophical analysis]. Sotsis - Sociological Studies. 7. pp. 48-54.

4. Abramov, R.N. (2017) Soviet Technocratic Mythologies Myth as the Form of Lost Chance Theory: on the Case of the History of the Cybernetics in the USSR. Sotsiologiya nauki i tekhnologiy - Sociology of Science and Technology. 2. pp. 63-79. (In Russian).

5. Nikolaev, A.N. (2018) Stanovlenie i transformatsiya sovetskoy tekhnokraticheskoy elity [Formation and transformation of the Soviet technocratic elite]. Vestnik PNIPU. Kul'tura. Istoriya. Filosofiya. Pravo. 2. pp. 83-95. DOI: 10.15593/perm.kipf/2018.2.07

6. Kosterev, A.G. \& Litvinov, A.V. (2016) The professorial corps of the higher school in the context of Soviet modernization. Vestnik Tomskogo gosudarstvennogo universiteta - Tomsk State University Journal. 403. pp. 69-78. (In Russian). DOI: 10.17223/15617793/403/12

7. Zemtsov, B.N. (2014) The Soviet tehnokratizm in 1917 -1930s. Gumanitarnyy vestnik (MGTU im. N.E.Baumana) - Humanities Bulletin of BMSTU. 3(17). (In Russian). DOI: 10.18698/2306-8477-2014-3-187

8. Kasavin, I.T. (2015) Megaproekty i global'nye proekty: nauka mezhdu utopizmom i tekhnokratizmom [Megaprojects and global projects: the science between utopianism and technocracy]. Voprosy filosofii. 9. pp. 40-57.

9. Kuteynikov, A.V. (2011) Akademik V.M. Glushkov i proekt sozdaniya printsipial'no novoy (avtomatizirovannoy) sistemy upravleniya sovetskoy ekonomikoy v 1963-1965 gg. [Academician V.M. Glushkov and the project of creating a fundamentally new (automated) control system for the Soviet economy in 1963-1965]. Ekonomicheskaya istoriya. Obozrenie. 15. pp. 139-156.

10. Petrakov, N.Ya. (1999) Razmyshleniya nad novoy knigoy. Akademik Fedorenko o zhizni i o sebe [Reflections on a new book. Academician Fedorenko about life and about himself]. Vestnik Rossiyskoy akademii nauk. 69(9). pp. 840-842.

11. Demin, A.N. (2009) Methodological and ideological lessons by Pobisk Georgievich Kouznetzov (on the 85th Anniversary). Chelovek. Soobshchestvo. Upravlenie - Human. Community. Management. 2. pp. 32-41. (In Russian).

12. Kuteynikov, A.V. \& Shilov, V.V. (2013) The last attempt to rehabilitate the project of the National System of Automatic Control of the Economy (OGAS): A. I. Kitov's 1985 letter to M.S. Gorbachev. Voprosy istorii estestvoznaniya i tekhniki. 2. pp. 100-109. (In Russian).

13. Muzykantsky, A.I. \& Yakovenko, I.G. (2011) Manikheystvo i gnostitsizm: kul'turnye kody russkoy tsivilizatsii [Manichaeism and Gnosticism: cultural codes of Russian civilization]. Moscow: Russkiy put'.

14. Yakovenko, I.G. (1999) Dolzhnoe i sushchee kak kategorii kul'turno-istoricheskogo protsessa (na materiale Rossii) [Due and being as a category of cultural and historical process (a case study of Russia)]. Abstract of Culture Studies Cand. Diss. Moscow.

15. Struktura innovatsionnogo protsessa. Trudy konferentsii [The structure of the innovation process. Conference proceedings]. Moscow: VNIISI. 